\title{
A Interface Prótese Parcial Removível / Periodontia: Revisão de Literatura
}

\section{Relationship between Removable Partial Denture and Periodontics: Literature Review}

\author{
Myriam Kapczinski*; ${ }^{a *}$ Débora Aline Budke Chiarellia; Caroline Kappes ${ }^{\mathrm{a}}$ \\ ${ }^{a}$ Universidade Federal do Rio Grande do Sul, Faculdade de Odontologia, RS, Brasil. \\ *E-mail: mpkapczinski@uol.com.br \\ Recebido: 11 de abril de 2015; Aceito: 15 de dezembro de 2015
}

\begin{abstract}
Resumo
Considerando a interface periodontia e prótese dentária para a elaboração de um plano de tratamento integrado em clínica odontológica, é importante discutir os critérios adotados em cada uma destas especialidades, no sentido da manutenção funcional de uma reabilitação protética com boa expectativa de duração. Esta revisão teve como objetivo analisar os estudos científicos presentes na literatura, no que tange à condição periodontal dos dentes suporte e o seu prognóstico para a utilização de próteses parciais removíveis, quando o nível de inserção óssea estiver diminuído. Foram analisados artigos selecionados das seguintes bases: Biblioteca Virtual em Saúde (BVS), PubMed (NCBI) Medline, Lilacs (Literatura Latinoamericana e do Caribe em Ciências da Saúde) e BBO (Bibliografia Brasileira de Odontologia), envolvendo o período de 1966 a 2015. Os trabalhos foram selecionados após triagem visando a compatibilidade com o tema desta revisão. Os estudos analisados, laboratoriais e de acompanhamento clínico mostram que os dentes suporte para uma prótese parcial removível cuja inserção óssea tenha sido reduzida devido a doença periodontal prévia podem apresentar menor tempo de sobrevivência se comparados a dentes hígidos periodontalmente. É necessário pelo menos uma inserção óssea mínima de $50 \%$, ou seja, uma proporção coroa-raiz de 1:1 para que este resista biomecanicamente à carga. Adicionalmente, o design da prótese parcial removível e um rígido controle de higiene bucal são fundamentais para o sucesso do tratamento.

Palavras-chave: Odontologia. Prótese Parcial Removível. Reabsorção Óssea.
\end{abstract}

\begin{abstract}
Considering the dental prosthesis and periodontal interface for the development of an integrated treatment plan for dental clinic, it is important to discuss the criteria adopted for each of these specialties regarding a long time prosthetic rehabilitation. This review aimed at analyzing scientific studies regarding the periodontal condition of the teeth and the prognosis for use of removable partial dentures, when the bone insertion level is decreased. The selected articles were analyzed from the following bases: Biblioteca Virtual em Saúde (BVS), PubMed (NCBI) Medline, Lilacs (Literatura Latinoamericana e do Caribe em Ciências da Saúde) and BBO (Bibliografia Brasileira de Odontologia) concerning the period 1966-2015. The studies were selected after screening to check the compatibility with the subject of this review. The studies reported that the teeth support for a removable partial denture whose bone insertion has been reduced due to prior periodontal disease may have shorter survival in mouth, when compared to periodontally healthy teeth. It requires at least a minimum bone attachment than 50\%, or a crown-root ratio of 1: 1 to provide biomechanical resistance to load. Additionally, the design of the removable partial denture and a stringent oral hygiene control are fundamental to a successful treatment.
\end{abstract}

Keywords: Odontology. Removable Partial Denture. Bone Resorption.

\section{Introdução}

A expectativa de vida atual da população brasileira é de 73,48 anos e a previsão para 2050 é de que atinja 81,3 anos ${ }^{1}$. No passado, o envelhecimento era sinônimo de edentulismo. No entanto, a perda dentária relaciona-se com a precariedade da saúde bucal. Em razão do avanço das técnicas odontológicas e a disponibilização de serviços à população, os fatores deletérios foram reduzidos e o número de usuários de próteses totais diminuiu, tornando as alternativas de tratamento do paciente parcialmente edêntulo ainda mais importantes. O tratamento reabilitador em pacientes parcialmente edêntulos pode ser realizado com prótese parcial removível - PPR, prótese parcial fixa dento-suportada - PPFDS ou implantosuportada - PPFIS. A terapia com prótese parcial removível - PPR é uma boa alternativa reabilitadora, pois preserva as estruturas remanescentes, desde que seja bem planejada. Não tem como única função a reabilitação de dentes e tecidos moles perdidos, mas também incrementa a fonética, estabiliza e aumenta a eficiência mastigatória. Além disso, alguns procedimentos de preparo e de confecção deste tipo de prótese são mais simples e têm menor custo, não requerendo um longo período de tempo, tornando-se menos cansativos e onerosos para o paciente.

Durante o uso de uma PPR, diferentes vetores de forças incidem sobre os dentes que suportam o aparelho. Há inserção e remoção várias vezes ao dia pelo usuário, e sabe-se que mesmo que exista um braço de reciprocidade bem desenhado em cada grampo, alguma tensão é passada ao dente pilar.

A resiliência existente entre fibromucosa de apoio na região edêntula é muito maior do que a do conjunto denteperiodonto, o que gera inevitavelmente grandes variações de 
tensão aplicadas aos dentes durante as atividades funcionais. Há movimentação do aparelho nos sentidos vertical, longitudinal e sagital, decorrente não só desta diferença tecidual, mas como consequência de forças mastigatórias.

Os recursos disponíveis atualmente para tratamento periodontal permitem manter saudavelmente em boca dentes com pequena inserção óssea remanescente (em torno de 30\%).

Um questionamento deve então ser realizado: estes dentes podem ser mantidos e submetidos a esforços de inserção e de remoção da prótese, bem como à incidência de forças decorrentes da mastigação? Quais as expectativas de longevidade de um tratamento proposto nestas condições?

Torna-se então de grande relevância o conhecimento da literatura disponível sobre o tema para fundamentar a elaboração de planos de tratamentos para pacientes nestas condições. Esta revisão teve como objetivo analisar os estudos científicos presentes e relevantes na literatura, referentes à condição periodontal dos dentes suporte de PPR e o prognóstico para a utilização deste tipo de prótese ao longo do tempo.

\section{Desenvolvimento}

A busca dos documentos foi realizada na Biblioteca Virtual em Saúde - BVS e no PubMed (NCBI), com uma pesquisa na base de dados Medline (MEDlars on Line, Literatura Internacional), Lilacs (Literatura Latinoamericana e do Caribe em Ciências da Saúde) e BBO (Bibliografia Brasileira de Odontologia) com as seguintes palavras-chave bone loss, alveolar loss, periodontal loss, removable partial denture, e abutment teeth. Os artigos foram selecionados a partir da leitura de seus resumos e novamente triados de acordo com o tema específico desta revisão de literatura, de 1966 até 2015.

Nesta revisão, serão abordadas duas questões principais para a reabilitação com PPR: as considerações sobre o funcionamento biomecânico deste tipo de aparelho e a influência do design da armação metálica relacionado às condições periodontais do paciente. Os estudos selecionados são eminentemente de acompanhamento clínico e alguns laboratoriais, cuja metodologia contribui no entendimento do tema proposto.

$\checkmark$ Biomecânica em PPR: O planejamento de uma PPR deve respeitar os princípios biomecânicos, a fim de que se neutralize a atuação das forças intra-orais sobre os dentes suporte, diminuindo sua movimentação intra bucal $^{2}$.

Uma PPR de extremo livre realiza pelo menos três tipos de movimentos. Um deles é a rotação sobre o eixo da linha de fulcro (alavanca), quando sob a aplicação de uma carga na base do extremo livre. Esta, então, se desloca no sentido dos tecidos de suporte do rebordo alveolar do mesmo lado. Para minimizar este tipo de movimento, deve-se realizar uma excelente moldagem que permita a perfeita adaptação da base da prótese à mucosa subjacente. O segundo movimento é a rotação sobre o eixo longitudinal, que pode ser evitado pelos componentes rígidos dos retentores diretos sobre os dentes suporte, bem como pela capacidade de resistência ao torque do conector maior. O movimento de torque é minimizado na presença de um pilar posterior, ou seja, nas situações de classes III ou IV de Kennedy. O terceiro movimento é a rotação do eixo vertical, o qual ocorre durante a função mastigatória, à medida que forças oclusais incidem nos sentidos diagonal e horizontal, podendo ser evitado pela ação dos braços de reciprocidade dos grampos e dos conectores menores em contato com as superfícies verticais dos dentes. As forças excessivas aos dentes pilares devem ser controladas para obtermos o sucesso do tratamento ${ }^{3}$.

Feingold et $a l .{ }^{4}$ monitoraram o efeito da aplicação de cargas em PPR com extremo livre distal em um modelo de estudo através de uma técnica fotográfica, em que se utilizou duas câmeras: uma para vista frontal e outra para lateral dos modelos. Foram analisados sete diferentes tipos de design de grampos: com um braço envolvendo a lingual e um braço de retenção vestibular (Akers) e do tipo Roach-T, variando a localização do apoio oclusal na mesial ou distal, e na presença ou ausência de plano guia. A aplicação de cargas verticais de $1,4 \mathrm{Kg}$ nas selas da prótese transmitiram forças à região do apoio oclusal e aos componentes dos grampos, causando movimentos na sela da prótese e nos dentes pilares. Estes autores concluíram que o grampo do tipo Roach-T produz movimento significativamente maior no dente pilar e na sela da prótese. Neste trabalho in vitro, a posição do apoio oclusal na mesial ou na distal não interferiu na direção do movimento do dente pilar e todos os tipos de designs de próteses provocaram movimentação no dente suporte.

$\mathrm{O}$ vetor de forças sobre um dente pilar de um paciente parcialmente edêntulo em ambos os arcos foi avaliado com o uso de uma PPR de extensão distal. Uma coroa teste foi confeccionada para o primeiro pré-molar esquerdo mandibular, periodontalmente saudável, com áreas de apoio oclusal mesial e distal e contorno vestibular, com retenções tanto mesial quanto distal para os grampos do tipo barra de contato e circunferenciais-modificados. Este estudo mostrou que o design dos grampos influenciou diretamente na direção e na magnitude da transmissão da força. Concluiu-se, dessa maneira, que a menor força foi observada para o dente pilar quando o apoio mesial foi utilizado em comparação com o apoio distal. A transmissão de força para o dente pilar foi maior quando uma carga vertical foi aplicada sobre a base da prótese no mesmo lado do que quando aplicada ao lado oposto $^{5}$.

Costa et al.$^{6}$ confeccionaram três modelos para simular um arco inferior Classe II de Kennedy, nos quais com auxílio da técnica fotoelástica foram testadas quinze próteses com selas de cinco comprimentos diferentes, utilizando os retentores barra-T, com apoios oclusais e planos guias proximais, barra-I e circunferencial Akers com apoio mesial. Todos foram ajustados aos padrões fotoelásticos e submetidos previamente a uma carga uniformemente distribuída e, em seguida, por 
uma carga localizada sobre o último dente artificial. As selas foram então encurtadas e os testes repetidos. As análises quantitativas e qualitativas de intensidade de tensão foram feitas manual e fotograficamente, respectivamente. $\mathrm{O}$ estudo concluiu que o retentor barra-I, seguido pela barra de $\mathrm{T}$, demonstraram a melhor distribuição de carga entre os dentes e o rebordo alveolar. O retentor circunferencial Akers causou maior concentração de tensões entre os ápices dentários. Portanto, a distribuição das tensões foi influenciada pelo tipo de retentor, pelo comprimento da sela e pela forma de aplicação da carga. Selas longas e cargas uniformemente distribuídas demonstraram melhor distribuição do estresse sobre as estruturas de apoio

\subsection{O design de PPR e as condições periodontais}

Com o diagnóstico/prognóstico periodontal prévio à confecção da prótese, pode-se avaliar a sobrevivência dos dentes suporte da prótese ao longo do tempo. Dentes suporte com prognóstico periodontal favorável tem um risco 9,3 vezes ou $830 \%$ menor de perda, comparado com um prognóstico que não seja favorável. Um prognóstico periodontal bom refere-se uma perda óssea inferior a $25 \%$, uma profundidade de sondagem da bolsa menor que $3 \mathrm{~mm}$, sem envolvimento de furca e dente sem mobilidade. Os dados também mostraram um risco 3,05 vezes maior para a perda dentária, com pilares de PPR em comparação com os pilares de $\mathrm{PPF}^{7}$.

A mobilidade dentária causada por alterações inflamatórias do ligamento periodontal pode ser reversível se a doença periodontal for tratada com a remoção do biofilme subgengival. Entretanto, se a mobilidade for causada pela grande perda de suporte ósseo, e a proporção coroa/raiz for maior do que 1:1, este não é adequado para ser suporte de $\mathrm{PPR}^{8,9}$.

Em casos de doença periodontal avançada, tendo os dentes remanescentes com extrema redução dos tecidos de suporte, em conjunto com uma mobilidade dentária progressiva, pode haver risco de que as forças geradas durante a função possam romper mecanicamente os constituintes remanescentes do ligamento periodontal, levando à perda dentária. Portanto, somente com uma contenção ou splint seria possível manter estes dentes, distribuindo-os na arcada de modo que limitasse a sua movimentação ${ }^{2}$.

Addy e Bates ${ }^{10}$ acompanharam 45 pacientes usuários de PPR e verificaram que o uso da PPR favoreceu o acúmulo de placa, principalmente na superfície lingual e vestibular dos dentes, sendo que PPR inferiores com conectores maiores, do tipo placa lingual, acumulam significativamente mais placa bacteriana do que a barra lingual. Quanto maior o tempo de uso da prótese (comparando o uso só durante o dia ou durante o dia/noite), maior é o acúmulo de placa e maior o sangramento gengival. Outra constatação importante do estudo é que a PPR causa aumento de placa no arco oposto à prótese, devido ao diminuído potencial de auto-limpeza dos tecidos moles pela saliva e do processo mastigatório, associado à higiene bucal deficiente. Os autores também relatam que o impacto periodontal tende a ser menor e menos relevante na utilização de próteses fixas do que de próteses parciais removíveis. Entretanto, os efeitos negativos não justificam a rejeição das próteses parciais removíveis, desde que tenham suas indicações feitas corretamente.

No estudo longitudinal de 10 anos de acompanhamento, 30 pacientes usuários de PPR foram examinados anualmente. Nos exames de reavaliação, foram monitoradas a atividade de cárie e a saúde periodontal com análise do índice de placa, índice gengival, profundidade de sondagem e mobilidade dentária dos dentes remanescentes com $75 \%$ de inserção periodontal. Durante as consultas de acompanhamento, foram realizados procedimentos odontológicos curativos e corretivos que o paciente necessitasse, além da motivação e orientação de higiene. Este estudo concluiu que o uso de PPR por si só não causa lesões cariosas nem periodontais, pelo contrário, é um valioso tratamento para pacientes com reduzido número de dentes. Portanto, a PPR pode aumentar o acúmulo de placa, mas se nos exames regulares o paciente for remotivado e reinstruído quanto à higiene bucal, pouco ou nenhum dano será causado aos dentes remanescentes ${ }^{11}$.

Em um estudo longitudinal de acompanhamento de cinco e 10, anos, realizado pela equipe de Behr et al. ${ }^{12}$, concluiu-se que complicações biológicas como cárie foram notadas em $58,4 \%$ dos pacientes (após 5 anos) e 39, 6\%, (após 10 anos); e doença periodontal em 35,6\% dos pacientes (após 10 anos), os quais apresentaram inflamação periodontal nos dentes pilares de prótese parcial removível. Ainda foi observado o aumento de acúmulo de placa ou excessiva carga não-axial distribuída nos dentes pilares.

Em outro estudo longitudinal, 36 pacientes idosos, usuários de PPR, foram acompanhados durante 30 meses. Após o tratamento periodontal, foram aleatoriamente divididos em dois grupos iguais, um dos quais foi tratado com conectores maiores tipo placa lingual e com barra lingual. A proximidade dos conectores maiores de PPR não é danosa para a saúde periodontal, desde que o paciente tenha um bom controle de placa. A barra lingual é o conector maior mandibular mais utilizado, devido à sua simplicidade. Já nos casos em que a maioria dos dentes posteriores foi perdida, com extremo livre bilateral, há a necessidade de adição de retenção indireta, por isso, a placa lingual pode ser indicada para evitar os movimentos horizontais de rotação da prótese e também para esplintar dentes com muita mobilidade. O acúmulo de placa é maior no conector maior do tipo placa lingual de PPR, no entanto, este não resultou em dano periodontal. Além disso, os pacientes tratados com placa lingual demonstraram menos mobilidade nos dentes, quando comparados com os pacientes tratados com barra lingual de PPR no final dos 30 meses de acompanhamento ${ }^{13}$.

Em dois pacientes classe I de Kennedy, fez-se a comparação entre três tipos de retentores: o grampo de fio dobrado, o grampo fundido de Akers e a coroa cônica telescópica. A avaliação incluiu a relação de distribuição de 
carga nas bases da prótese e a mobilidade dos dentes pilares periodontalmente tratados, por isso considerados saudáveis, em uma PPR de extremo livre. Concluiu-se que os diferentes retentores influenciam na distribuição da carga oclusal, sendo que esta distribuída à sela do extremo-livre está intimamente relacionada à rigidez de ligação do retentor. Outro fator importante é o apoio da mucosa, que é indispensável na partilha da carga oclusal com os diferentes retentores, mesmo com um retentor rígido como a coroa cônica telescópica. Entretanto, a mobilidade dos dentes pilares de todos os 3 tipos de retentores manteve-se dentro da "capacidade de mobilidade" dos dentes, na qual o complexo periodontal suporta as forças de movimentação, sendo classificada, segundo o estudo, de mobilidade fisiológica ${ }^{14}$.

Em ensaio clínico randomizado, foram comparados os grampos tipo barra-I e o grampo circunferencial, ao longo de cinco anos de acompanhamento e avaliando a taxa de sucesso das próteses. Trinta dos 134 PPR, ou seja 19\%, foram considerados fracassos, 5 devido a falhas no dente suporte: sendo destes dois abscessos periapicais agudos com impossibilidade de retratamento, uma fratura radicular, 2 casos de perda de suporte periodontal e 25 por causa da falta de uso da PPR para alimentar-se. Dentes suporte considerados desfavoráveis pelo estudo apresentavam menos de $70 \%$ de suporte ósseo, com proporção coroa-raiz menor que 1:1. Portanto, se a PPR for bem planejada, apoiada em pilares periodontalmente favoráveis e acompanhada por um rígido programa de manutenção de saúde bucal é uma modalidade de tratamento satisfatório ${ }^{15}$.

Foram avaliados neste estudo retrospectivo 74 pacientes com 101 próteses com coroas cônicas - CCRD, com grampos - PPR e com a combinação de coroas cônicas anteriores e grampos nos molares - CRPD, e além disso foram classificados de acordo com o desenho do suporte dental - linear, triangular e quadrangular. Os resultados periodontais como profundidade de sondagem e mobilidade dentária/ perda óssea (PTV - índice de abalo periodontal medido pelo dispositivo Periotest) de dentes pilares e não pilares foram reavaliados após 10 anos de inserção das próteses parciais removíveis. A taxa de exodontias indicadas após os 10 anos foi de 26,4\% para dentes pilares e $14,2 \%$ para dentes não pilares. Em geral, todos os resultados aumentaram, sendo que os dentes pilares mostraram piores condições periodontais que os não pilares, possivelmente devido à falta de um sistema de acompanhamento regular para a instrução e remotivação de higiene bucal durante o intervalo de 10 anos. Os dentes pilares de PPR apresentaram maior PTV e maior profundidade de sondagem $(3,2 \mathrm{~mm})$ do que os pilares dos outros tipos de prótese. As próteses CRPD apresentaram melhor desempenho em relação ao PTV, o que não pode ser explicado somente pela fixação da prótese nos pilares, mas também por apresentarem uma estruturação triangular com pilar distal ${ }^{16}$.

Um estudo in vitro com modelos fotoelásticos comparou a distribuição de tensão de três diferentes designs de PPR de extensão distal com dentes pilares com perda progressiva de $20 \%$ (com proporção coroa-raiz de 50/50) até 35\% (com proporção coroa-raiz de 60/40) de suporte periodontal. O estudo comparou os designs de retentor tipo barra-I, retentor de semi-precisão Tach-EZ e o retentor formado por anéis de fixação ERA, sendo que ambos os modelos de retentores foram testados com ou sem pilares esplintados. Um importante achado do estudo foi que a tuberosidade funciona como estrutura de apoio ativo quando há perda de suporte periodontal de até $35 \%$, recebendo parte da distribuição da carga no rebordo alveolar posterior entre o pilar e a tuberosidade. O retentor Tach-EZ apresentou menor estabilidade, quando comparado com os outros designs, pela falta de contenção e reciprocidade ${ }^{17}$.

Ma e Brudvik ${ }^{18}$ apresentaram relato de caso clínico cujo paciente apresentava uma extensa perda dentária anterior e os dentes remanescentes com grande mobilidade, devido à doença periodontal prévia com perda de 40 a $50 \%$ do osso alveolar. O paciente foi reabilitado com uma PPR de design não convencional, com apoio oclusal em todos os dentes, com planos guia na mesial e na distal dos dentes e conector principal do tipo placa palatina, com uma extensa área sem nenhum contato na superfície palatina dos dentes. Os grampos da PPR encontravam-se apenas na distal dos segundos molares. Este tipo de design permite reparos relativamente simples durante a vida útil da prótese, pois é possível acrescentar dentes que possivelmente serão perdidos. Esta modalidade de tratamento não só resolveu a falta de dentes como estabilizou os dentes remanescentes de um paciente com perda de inserção periodontal avançada. Ao envolver-se com os princípios orientadores como planos guias nas superfícies mesiais dos pilares anteriores e também nas superfícies distais dos pilares posteriores dos dentes remanescentes, com níveis variados de mobilidade, foram contidas em conjunto pela estrutura. De acordo com os autores, esta é uma opção de tratamento conservador, que oferece conforto e estética, melhorando a função mastigatória do paciente.

No estudo de Itoh et al. ${ }^{19}$, foram criados três modelos fotoelásticos de arcada classe I inferior, que diferiam apenas na quantidade e na configuração do suporte periodontal em torno dos primeiros pré-molares. Estes modelos foram utilizados para avaliar a tensão aplicada sobre os dentes pilares esplintados e o uso de uma PPR com retentor do tipo barra-I. Foram esplintados os dentes caninos e primeiro prémolar através de coroas metalo-cerâmicas unidas entre si. Os resultados deste estudo mostraram que a imobilização fixa de pilares periodontalmente comprometidos redistribuem efetivamente as forças às estruturas de apoio, porém o aumento do número de dentes esplintados não provoca uma diminuição proporcional dos níveis de tensão. Portanto, os modelos fotoelásticos não reproduzem identicamente as situações clínicas, mas sugerem que o design utilizado no estudo e o ajuste da armação metálica da PPR com esplintagem criteriosa preveniram o movimento de rotação 
da prótese, resultando na transferência de parte da carga ao rebordo edêntulo, diminuindo a concentração de carga aos dois pilares. A esplintagem extensiva do arco não resulta em dissipação proporcional de carga em dentes pilares com periodonto reduzido.

No estudo de Rudd e O'Leary ${ }^{20}$ foi testado o uso de próteses parciais removíveis após o tratamento periodontal. Em 12 pacientes foram utilizadas PPR para esplintar os dentes com mobilidade, sendo verificado que a mobilidade dentária permaneceu igual ou diminuiu. Entretanto, o estudo não foi considerado conclusivo por causa do curto período de tempo de acompanhamento. Os dados acumulados durante o período de dois anos indicaram a necessidade de cuidadoso planejamento, design apropriado, confecção adequada e ajuste nas próteses parciais removíveis com plano guia para a imobilização de dentes com mobilidade.

A resposta gengival de 10 indivíduos foi avaliada durante três semanas de uso de PPR provisória acrílica.O uso de PPR provisória com ou sem alívio na margem gengival causou alteração na saúde gengival como aumento de volume gengival e vários pontos de sangramento ${ }^{21}$.

Outro estudo que também avaliou a resposta gengival de 10 pacientes que usavam PPR provisória durante 12 horas diárias por três semanas analisou diferentes áreas de 1 a 3 $\mathrm{mm}$ com alívio e sem alívio junto a margem gengival. Este estudo mostrou que as alterações na saúde gengival ocorrem rapidamente após a inserção de uma PPR provisória, mesmo com a presença de alto nível de higiene bucal. Entretanto, alguns pacientes não seguiram rigorosamente as orientações do s pesquisadores. Os que realizaram mais de duas vezes ao dia a higiene bucal não acumularam placa. Não houve diferenças significativas nas alterações periodontais nas áreas com ou sem alívio da margem gengival, pois uma vez coberta a margem gengival com a PPR, há alteração na saúde gengival. Por isso, é aconselhado que o aparelho esteja localizado a uma distância de no mínimo $3 \mathrm{~mm}$ da margem gengival. O uso de PPR provisória por si só causa alteração na saúde da mucosa como o aumento de volume gengival. Entretanto, o índice de placa, o sangramento gengival e a profundidade da bolsa periodontal não apresentaram diferenças estatisticamente significativas em nenhuma área teste, ou seja, com $0,1,2$ ou $3 \mathrm{~mm}$ de alívio na prótese. Ainda assim, o autor sugere uma distância de $3 \mathrm{~mm}$ da margem gengival dentária ${ }^{22}$.

Considerando a importante interface periodontia e prótese na elaboração de um plano de tratamento, que propicie ao paciente a reabilitação funcional e estética, com boa expectativa de manutenção e funcionamento, é importante a discussão dos critérios adotados para cada especialidade, quando é proposta ao paciente a execução de uma PPR. O suporte periodontal dos dentes remanescentes é um fator de grande importância para o sucesso no tratamento reabilitador com PPR. Frequentemente, a decisão de usar ou não um dente como pilar é baseado no prognóstico periodontal favorável, sendo este um verdadeiro dilema por causa da escassez de provas sobre a relação preditiva entre o prognóstico periodontal e a sobrevivência dos dentes pilares, sendo a importância deste estudo a divulgação de evidência científicas que possam facilitar a tomada de decisões especialmente pelo protesista.

Entre os estudos analisados, há achados complementares e contraditórios. Estudos clínicos e epidemiológicos têm demonstrado que ambas as doenças cárie e periodontite são causadas pelo crescimento bacteriano, associado com a gravidade da doença e o aumento da severidade com a idade. Portanto, a motivação, a instrução e o cuidado profissional da higiene bucal previnem ou reduzem o progresso da cárie e da doença periodontal com um programa preventivo de acompanhamento. Desse modo, é possível manter um nível elevado de higiene oral, o que resulta em um mínimo progresso da cárie e de perda de suporte periodontal durante um prolongado período de tempo. Para eliminar os danos periodontais e possíveis perdas dentárias causadas pelas PPR, um sistema de revisões periódicas é fortemente recomendado ${ }^{11,13,15,16}$.

Quando se utiliza um sistema duplo de suporte (PPR dento-muco suportada), com apoio na estrutura dentária e no rebordo alveolar remanescente, como no caso de PPR com extensão-distal, faz-se necessário uma adequada distribuição de tensão em torno dessas estruturas, diminuindo, desse modo, a possibilidade de reabsorção óssea desigual. Este fenômeno geralmente começa na região da sela e pode progredir até o dente pilar. Em estágios mais avançados, pode haver a perda do dente suporte com o comprometimento do ligamento periodontal. As selas devem ser mais longas e com um amplo revestimento da superfície basal, uma vez que as selas curtas aumentam a concentração de tensão sobre as cristas residuais, levando a uma rápida e acentuada perda óssea, o que consequentemente irá conduzir à perda do dente suporte. Em relação à carga, o melhor desempenho foi observado quando a carga foi uniformemente distribuída, sendo que a localização da carga no último dente artificial induziu uma maior concentração de tensões no rebordo residual. Por isso, o dente pilar é o elemento mais adequado para receber e neutralizar as tensões quando comparado com a mucosa alveolar ${ }^{6,9}$.

Durante o planejamento de PPR, o cirurgião-dentista deve selecionar os retentores diretos adequados para cada caso, assegurando efetiva retenção e minimizando as forças prejudiciais aos pilares e aos tecidos suporte. Segundo Feingold et $a{ }^{4}{ }^{4}$, a posição do apoio oclusal dos retentores diretos tanto na mesial, quanto na distal não interfere na direção do movimento nos dentes suportes e todos os tipos de designs de retentores provocam o movimento mesial. Entretanto, McCartney ${ }^{5}$ concluiu que a menor força foi observada para o dente pilar quando o apoio mesial foi utilizado, em comparação com o apoio distal. Apoios oclusais distais, quando comparados aos mesiais, produzem maior movimentação do dente pilar, levando à sua rotação.

Os retentores diretos têm a função de reter e estabilizar a 
PPR ao dente suporte, sendo os grampos circunferenciais e barra de contato combinados para grandes espaços edêntulos e extremidades livres. Tanto o design circunferencial quanto o combinado com barra-I não diferem significativamente quanto à taxa de sucesso, cuidados de manutenção, efeitos sobre a saúde periodontal e incidência de cárie, quando os dentes pilares apresentam suporte ósseo favorável e for seguido um rígido controle de placa bacteriana. $\mathrm{O}$ grampo tipo barra de contato-T produz um movimento significativamente maior ao dente pilar e na sela da prótese, quando comparados com grampos circunferenciais de ação reversa. O retentor barra de contato formato I seguido pela barra em $\mathrm{T}$ demonstraram a melhor distribuição de carga entre os dentes e rebordo alveolar, entretanto o uso do retentor circunferencial Akers sem combinação com barra de contato e apoio oclusal mesial causou maior concentração de tensões entre os ápices dentários $^{4,15}$. A maior rigidez de ligação dos retentores diretos de PPR causa menor mobilidade aos dentes suporte, assim como proporcionam maior longevidade aos elementos dentários, se comparados aos grampos de fio dobrado em próteses parciais provisórias inteiramente acrílicas, que causam severos danos aos tecidos da cavidade bucal ${ }^{21,22}$.

Dentre os conectores maiores mandibulares, a barra lingual é o conector mais utilizado devido a sua simplicidade. Os conectores maiores, do tipo placa lingual, acumulam significativamente mais placa bacteriana do que a barra lingual, portanto os pacientes devem estar sempre em um rígido controle de manutenção ${ }^{10,13}$. No entanto, a placa lingual é indicada em casos de extremo livre bilateral para adição de retenção indireta, evitando movimentos de rotação da PPR, e também pode ser utilizada para a esplintagem de dentes com mobilidade aumentada, devido à grande perda de suporte periodontal.

Entre as possibilidades de tratamento para os pacientes parcialmente edêntulos com extremo livre distal que não possam receber implantes, estão o uso de cantilever em PPF e a PPR. Os pacientes, na maioria das vezes, preferem a PPF porque percebem maior conforto e facilidade de manutenção, no entanto, a PPF não pode oferecer a melhor biomecânica, devido a sua capacidade limitada de transferir forças oclusais para partes distantes do $\operatorname{arco}^{19}$. Portanto, a tuberosidade, assim como o apoio da mucosa oral do rebordo residual, funciona como estruturas de apoio adicional e recebem parte da distribuição da carga, quando há perda de suporte periodontal ${ }^{14,17,19}$. Porém, a PPR, além de causar aumento de placa adjacente à prótese, também aumenta o acúmulo no arco oposto a prótese, devido a diminuição do potencial de autolimpeza dos tecidos pela saliva, associados a higiene bucal deficiente ${ }^{10}$.

O uso de PPR com plano guia compondo a armação metálica favorece a estabilização de dentes periodontalmente enfraquecidos e diminui a mobilidade dos dentes. Considerando a associação PPR e PPF, a principal vantagem da esplintagem dos dentes suporte da PPR é a estabilização cruzada da arcada, pois os dentes de ambos os lados (considerando uma classe I de Kennedy) oferecem resistência às forças horizontais. A união de dois ou mais dentes através da esplintagem com PPF aumenta a área de ligamento periodontal, distribuindo as forças de maneira eficaz e reforçando o suporte periodontal reduzido. Em estudos laboratoriais, verifica-se que o aumento do número de dentes esplintados não causaria a diminuição proporcional nos níveis de tensão máxima aos dentes adicionados, mas há de se considerar as limitações de um ensaio in vitro ${ }^{9,19,20}$.

O prognóstico periodontal "bom" significa uma perda óssea inferior a $25 \%$, com profundidade de sondagem menor que $3 \mathrm{~mm}$, sem envolvimento de furca e ausência de mobilidade dentária. Kapur et al. ${ }^{5}$ consideraram como desfavorável os dentes suporte que apresentavam menos de $70 \%$ de suporte ósseo, a partir de um ponto $1 \mathrm{~mm}$ abaixo da junção amelocementária e com proporção coroa-raiz menor que 1:1,5 para pilar simples e 1:1, 25 para pilar duplo, sendo este o posicionamento mais extremo encontrado nesta revisão. Os dentes suporte devem apresentar 3/4 do nível ósseo alveolar, com no mínimo $50 \%$ de inserção periodontal, ou seja, uma proporção coroa-raiz de $1: 1^{7,9,11}$.

A principal causa de fracasso da PPR está relacionada com a perda de dentes pilares. No estudo de Kern e Wagner ${ }^{16}$, os pacientes usuários de PPR que não participaram do sistema de acompanhamento regular durante os 10 anos apresentaram taxa de extração de $26,4 \%$ para dentes pilares e $14,2 \%$ para dentes não pilares. Segundo Cabanilla et al. ${ }^{7}$, a taxa de sobrevida cumulativa foi de 13,8 anos, sendo que um total de 16 dos 226 dentes pilares foram perdidos, correspondendo $7,1 \%$ dos dentes. Além disso, os dados mostraram risco de 3,05 vezes maior de perda de dentes pilares de PPR, em comparação com pilares de PPF. Portanto, dentes suporte com um prognóstico inicial específico "bom" tiveram um risco 9,3 vezes menor de perda, quando comparado com qualquer outro prognóstico.

O design da PPR influencia no acumulo de biofilme bacteriano nos dentes suporte, sendo que pacientes portadores deste tipo de aparelho possuem taxas de sobrevida destes dentes menor do que os portadores de PPF. No entanto, dentre os fatores de insucesso em 10 anos de acompanhamento destacam-se a falta de comprometimento dos pacientes com a manutenção de sua boa saúde oral bem como fatores sistêmicos como idade e diabetes ${ }^{8,23}$.

Ainda há a necessidade de estudos que apontem a eventual associação do uso de PPR a fatores culturais e econômicos, uma vez que poderia se inferir que pacientes usuários de PPR teriam menor nível sócio-econômico e, portanto, prognósticos menos favoráveis em relação ao controle de placa.

\section{Conclusão}

A elaboração de um plano de tratamento integrado entre as especialidades prótese e periodontia deve ser cuidadosamente executada antes da abordagem clínica do paciente. Elementos 
dentários com suporte inadequado para PPR não devem ser mantidos em boca, pois tornariam o prognóstico clínico desta reabilitação protética potencialmente sombrio.

A PPR é uma alternativa de tratamento reabilitador para pacientes parcialmente edêntulos, e seu desenho deve ser muito bem planejado para que seja mantido o sucesso do tratamento ao longo do tempo, particularmente em dentes pilares com inserção óssea reduzida e histórico de doença periodontal. Para um dente ser suporte de PPR, deve apresentar no mínimo $50 \%$ de inserção periodontal, com proporção coroa-raiz de $1: 1$.

O principal objetivo de uma prótese é manter o equilíbrio entre a saúde e a função do sistema estomatognático, preservando as estruturas remanescentes da cavidade bucal em condições funcionais. Portanto, é necessário que haja equilíbrio entre as forças aplicadas aos dentes remanescentes e a capacidade do periodonto suportá-las. Este objetivo será alcançado com o planejamento criterioso do design da PPR e do cumprimento dos requisitos biomecânicos e rígida manutenção periodontal.

\section{Referências}

1. IBGE. Censo 2010. [acesso em 10 set 2014]. Disponível em http://censo2010.ibge.gov.br/resultados.

2. Di Fiore SR, Di Fiore MA, Di Fiore AP. Atlas de Prótese Parcial Removível: princípios biomecânicos, bioprotéticos e de oclusão. São Paulo: Santos; 2010.

3. Carr AB, Brown DT. McCracken Prótese parcial removível. São Paulo: Elsevier; 2012

4. Feingold GM, Grant AA, Johnson W. The effect of partial denture design on abutment tooth and saddle movement. J Oral Rehab 1986;13(6):549-57.

5. Mc'Cartney JW. Motion vector analysis of an abutment for a distal-extension removable partial denture: a pilot study. J Prosthet Dent 1980;43(1):15-21.

6. Costa MM et al. Photoelastic study of the support structures of distal-extension removable partial dentures. J Prosthet Dent 2009; 18:589-95

7. Cabanilla LL, Neely AL, Hernandez F. The relationship between periodontal diagnosis and prognosis and the survival of prosthodontic abutments: a retrospective study. Quint Int 2009;40(10):821-31.

8. Müller S, Eickholz P, Reitmeir P, Eger T.Long-term tooth loss in periodontally compromised but treated patients according to the type of prosthodontic treatment: a retrospective study. J Oral Rehab 2013;40:358-67.

9. Phoenix RD, Cagna DR, Defreest CF. Prótese parcial removível: clínica de Stewart. Rio de Janeiro: Quintessence; 2007.

10. Addy M, Bates F. Plaque accumulation following the wearing of different types of removable partial dentures. J Oral Rehab 1979;6(2):111-7.

11. Bergman B, Hugoson A, Olsson CO. Caries, periodontal and prosthetic findings in patients with removable partial dentures: a ten-year longitudinal study. J Prosthet Dent 2009;48(5):506-14.

12. Behr M, Zeman F, Passauer T, Koller M, Hahnel S, Buergers $\mathrm{R}$, et al. Clinical performance of cast clasp-retained removable partial dentures: a retrospective study. Int J Prosth 2012;25(2):138-44.

13. Akaltan F, Kaynak D. An evaluation of the effects of two distal extension removable partial denture designs on tooth stabilization and periodontal health. J Oral Rehab 2005;32(11):823-9.

14. Igarashi Y, Ogata A, Kuroiwa A, Wang CH. Stress distribution and abutment tooth mobility of distal-extension removable partial dentures with different retainers: an in vivo study. J Oral Rehab 1999;26(2):111-6.

15. Kapur KK, Deupree R, Dent RJ, Hasse AL. A randomized clinical trial of two basic removable partial denture designs. Part I: comparison of five-year success rates and periodontal health. J Prosthet Dent 1994;72(3):268-82.

16. Kern M, Wagner B. Periodontal findings in patients 10 years after insertion of removable partial dentures. J Oral Rehab 2001;28(11):991-7.

17. Berg T, Caputo AA. Maxillary distal-extension removable partial denture abutments with reduced periodontal support. J Prosthet Dent 1993;70(3):245-50.

18. Ma PS, Brudvik JS. Managing the maxillary partially edentulous patient with extensive anterior tooth loss and advanced periodontal disease using a removable partial denture: a clinical report. J Prosthet Dent 2008;100(4):259-63.

19. Itoh H, Caoutto AA, Wylie R, Berq T. Effects of periodontal support and fixed splinting on load transfer by removable partial dentures. J Prosthet Dent 1998;79(4):465-71.

20. Rudd KD, O'Leary TJ Stabilizing periodontally weakened teeth by using guide plane removable partial dentures: a preliminary report. J Prosthet Dent,1966;16:721-7

21. Hobkirk JA, Strahan JD. The influence on the gingival tissues of prostheses incorporating gingival relief areas. J Dent 1979:7(1):15-21.

22. Orr S, Linden GJ, Newmann HN. The effect of partial denture connectors on gingival health. J Clin Periodontol 1992:19(8):589-94.

23. Walter MH, Marré B, Vach K, Strub J, Mundt T, Stark H. Management of shortened dental arches and periodontal health: 5-year results of a randomised trial. J Oral Rehab 2014;41:515-22 